\title{
For Rich
}


Carmen M. Mangion - 9781526135285 